\title{
Cryogenic Probe Station for use in Automated Microwave and Noise Figure Measurements
}

Susan R. Taub and Samuel A. Alterovitz

Lewis Research Center

Cleveland, Ohio

Paul G. Young

University of Toledo

Toledo, Ohio

and

Ben T. Ebihara and Robert R. Romanofsky

Lewis Research Center

Cleveland, Ohio

Prepared for the

Automated RF Techniques Group Meeting cosponsored by the IEEE, MTIS and ARFTG

San Diego, California, May 27, 1994 


\title{
CRYOGENIC PROBE STATION FOR USE IN AUTOMATED MICROWAVE AND NOISE FIGURE MEASUREMENTS
}

\author{
Susan R. Taub, Samuel A. Alterovitz, Paul G. Young*, Ben T. Ebihara, Robert R. Romanofsky \\ NASA Lewis Research Center \\ Cleveland, $\mathrm{OH} 44135$ \\ *University of Toledo \\ Electrical Engineering Department \\ Toledo, $\mathrm{OH} 43606$
}

\begin{abstract}
A cryogenic measurement system capable of performing on-wafer RF testing of semiconductor devices and circuits has been developed. This "CryoProbe Station" can waferprobe devices and circuits at cryogenic temperatures, thus eliminating the need for wire bonds. The system operates under vacuum created by a sorption pump. It uses an open cycle cooling system that can be cooled with either liquid nitrogen or liquid helium. Presently, it can reach temperatures, as low as $80 \mathrm{~K}$ and $37 \mathrm{~K}$ for each of the coolants, respectively. The temperature can be raised using a heater and it is stabilized to within $0.2 \mathrm{~K}$ by use of a temperature controller. The CryoProbe Station features a 1 by 2 inch stage that can hold large circuits and calibration standards simultaneously. The system is used with a Hewlett Packard $8510 \mathrm{C}$ Automatic Network Analyzer (ANA) to obtain S-parameter data over the frequency range 0.045-26.5 GHz. S-parameter data on HEMT (high electron mobility transistors) devices has been obtained with this station. With the use of DEEMBED software from NIST, detailed transmission line studies have been performed. Although the CryoProbe Station is designed for frequencies up to $26.5 \mathrm{GHz}$, useful transmission line data has been obtained for frequencies as high as $40 \mathrm{GHz}$. The CryoProbe station has also been used with the ATN noise figure measurement system to perform automatic, temperature dependent noise figure measurements.

\section{INTRODUCTION}

The ability to perform microwave tests at cryogenic temperatures is becoming vital. Many RF devices must operate in low-temperature environments. These environments may be naturally occurring, such as in space, or, they may be created artificially for technologies such as, superconductors. In any case, RF circuits and their components, both active and passive, must be characterized at these temperatures. The resulting data is needed to properly design and implement cryogenic circuits. This is important, since the characteristics of most microwave components change significantly with temperature. Fortunately, the changes that occur at low temperatures are more often for the better.
\end{abstract}


It is now known that for many RF devices, characteristics such as: $f_{t}, f_{m a x}$ and gain $[1,2]$, and noise figure $[3,4]$ improve at cryogenic temperatures. The main explanation for this can be found in Figure 1. Figure 1 shows the Hall mobilities for several III-V materials. The mobilities of these materials increase significantly in inverse proportion to temperature. This means that the speed of devices fabricated from these materials increases at cryogenic temperatures, which explains the increase in $f_{t}$ and $f_{\max }$. Higher mobilities also lead to improvements in noise figure. In addition to basic material improvements at cryogenic temperatures, there are technologies that absolutely require these temperatures. One such example is superconductors. But there are also some very high mobility technologies, such as: indium arsenide (InAs) and indium antimonide ( $\mathrm{InSb}$ ) that also must be used at lower temperature. Figure 2 shows the intrinsic carrier concentrations of these materials and how they decrease with temperature. The carrier concentrations of $\operatorname{InAs}$ and $\operatorname{InSb}$ are extremely high at room temperature. These materials, therefore, must be used at cryogenic temperatures where they will no longer be intrinsically conductive.

In any type of microwave characterization it is advantageous to test the component directly, without the interference of wire bonds or test fixtures. At cryogenic temperatures this is particularly true, since certain types of component contact, such as wire bonds, become very unreliable at low temperatures. A cryogenic probe system not only eliminates the need for wire bonds and test fixtures, but also easily accommodates calibration at testing temperatures and the characterization of many components, very quickly, in a single run. There have been several designs of cryogenic, microwave probe systems $[5,6,7,8]$. The primary function of these systems was to test discrete devices. Most do not have sufficient space to test a large circuit sample and a separate calibration standard substrate $[6,7,8]$. In addition, most of theses systems $[5,6,7]$ used either liquid nitrogen or helium as the coolant. In order to be able to use both, interchangeably, without having to purchase a second coolant transfer line, modifications must be made to the coolant dewar.

This paper describes a cryogenic microwave probe system that can accommodate large samples, calibration at testing temperatures and is suitable for either liquid nitrogen or helium coolants. A full description of the system, including evacuation and cooling times is given. Also presented is some sample temperature-dependent S-parameter and noise figure data.

\section{SYSTEM DESCRIPTION}

A block diagram of the CryoProbe Station system is shown in Figure 3. The system consists of the CryoProbe station, vacuum pumps, coolant system, and a microscope. A 
photograph of the CryoProbe Station and the inside of its chamber are shown in Figures $4 a$ and $4 \mathrm{~b}$, respectively. In order to be able to view the samples in the chamber, windows were put in the top and front of the chamber. Because of the wide distance from the top window to the sample stage, an Olympus SZ11 zoom stereo microscope was used to view the samples and position the probe tips. This microscope has a $73 \mathrm{~mm}$ depth of focus, with a coaxial illumination system. The chamber contains the sample stage, cooling head of the refrigerator, temperature sensors and microwave probes. It was designed to have a low volume so that cooling could be done as quickly as possible. The dimensions of the sample stage are 1 by 2 inches. This provides sufficient surface area for the placement of both the calibration standards and the samples, together, on the stage. The stage was made of a 0.3 inch thick piece of OFHC (oxygen-free, high conductivity) copper, in order to enhance its thermal conductivity. Silicon temperature sensors were placed on the sample stage and at the tip of the cooling head. Microwave contact to the samples is achieved through the use of PicoProbe microwave probes. They were chosen because of the flexibility of their tips. Although the microwave probes are located inside the chamber, the probe manipulators are located on the outside in order to reduce the chamber volume and the complexity of the system. The Thermionics EC Series Precision Manipulators used have 0.1 mil resolution and can move the probes over the entire area of the sample stage, using a metal bellows coupling system.

In the CryoProbe station, cryogenic temperatures are achieved by first evacuating the sample chamber, after which a cryogen is used to cool the stage. This cryogen is either liquid nitrogen or helium. Vacuum is created within the CryoProbe station by the use of two pumps. A mechanical pump is used to rough down the chamber of the station to 200 mTorr. This is accomplished in approximately 7 minutes. At this point the mechanical pump is turned off and the sorption pump takes over. Evacuation to $5 \mathrm{mT}$ Trr is reached after an additional 13 minutes. The pressure within the chamber reaches its minimum value of less than $3 \mathrm{mTorr}$ in a total time of 43 minutes. Pressure is monitored by a 917 Pirani vacuum gauge from MKS instruments.

After a vacuum of 5 mTorr is reached, the coolant is introduced. An open cycle cryogenic cooling system was used, as opposed to a closed cycle system, in order to minimize noise and vibrations. Vibration reduction is particularly important in an environment that supports wafer probing. This system consists of the Heli-tran LT-3B refrigerator and the LT-3-110 flexible transfer line, manufactured by APD Cryogenics Inc. The refrigerator is inserted into the back of the CryoProbe station and attached underneath the sample stage. It is used without radiation sheilding. The flow rate of the coolant is monitored by an APD Cryogenics flow meter. 
The cooling times for both liquid nitrogen and helium are shown in Figure 5. The minimum temperatures reached are $80 \mathrm{~K}$ and $37 \mathrm{~K}$ for nitrogen and helium coolants, respectively. The overall cooling time for liquid nitrogen is only a little over 30 minutes. In order to be able to use the same flexible transfer line to transfer both the liquid nitrogen and the liquid helium, modifications had to be made to the liquid nitrogen dewar. Since the manifolds used for liquid helium and nitrogen are different, the liquid nitrogen dewar had to be fitted with a liquid helium manifold.

in addition to the temperatures previously mentioned, the CryoProbe station can also be stabilized at higher temperatures. Once the system has been cooled, a Lakeshore DRC-91C temperature controller is used to heat the chamber to the desired temperature. At lower temperatures, the temperature can be stabilized to within $0.2 \mathrm{~K}$. For temperatures closer to room temperature, stabilization becomes more and more difficult and the settings on the temperature controller must be adjusted accordingly.

\section{MEASUREMENT EXAMPLES}

Because of the large size of the stage in the CryoProbe station, many types of devices and circuits can be accommodated. Measurements have been performed on FET devices and transmission lines. When measuring the performance of $0.1 \mu \mathrm{m}$ gate-length pseudomorphic $\ln _{0.52} \mathrm{Al}_{0.48} \mathrm{As} / \mathrm{In}_{\mathrm{x}} \mathrm{Ga}_{1-\mathrm{x}} \mathrm{As}$ ( $\mathrm{X}=0.85$ and 0.95 ) MODFETs, an improvement in $\mathrm{f}_{\mathrm{t}}$ of over $33 \%$ occurred at $77 \mathrm{~K}$ as compared to room temperature [9]. Coplanar Waveguide (CPW) transmission lines were characterized in terms of their attenuation constant, as a function of geometry, frequency and resistivity. To perform this study, the CryoProbe system was used with an HP 8510C ANA and DEEMBED software from NIST [10]. It was discovered that for transmission lines on silicon, GaAs and diamond substrates, there was at least a $0.25 \mathrm{~dB} / \mathrm{cm}$ improvement in attenuation at 77K [11].

Using the CryoProbe station with Automatic Testing and Networking (ATN) Inc.'s NP5 noise figure system enabled temperature dependent noise figure data to be obtained for a pseudomorphic HEMT structure. It was necessary to minimize the electrical distance between the CryoProbe station and the tuner of the noise figure system, so that range of impedance magnitudes would not be too restricted due to extra line loss. If this was not done, the measurements on devices requiring a large source reflection coefficient for optimum noise figure would be less accurate. Noise figure measurements were performed with this system and a Hewlett Packard $8970 B$ noise figure meter. The ATN system uses an electronically adjusted tuner incorporating PIN diodes to provide up to 241 repeatable impedance states and radial 
coverage of the Smith chart. A calibration step is performed which determines the amount of noise injected from port one with different impedance settings. Available gain, as opposed to insertion gain, is calculated by measuring the device's output reflection coefficient in another calibration step. Second stage noise, or system noise figure, is accounted for in the normal fashion [12]. A simple guide describing the underlying theory of the system is available [13].

The HEMT structure that was analyzed is shown in Figure 6. This material was grown by Spire Corporation using Metal-Organic Chemical Vapor Deposition (MOCVD) and the subsequent HEMT devices were fabricated by Texas Instruments [14]. The devices had the following features: $0.25 \mu \mathrm{m}$ gate lengths, $0.75 \mu \mathrm{m}$ gate widths, approximately $300 \mathrm{mS} / \mathrm{mm} \mathrm{dc}$ transconductance $\left(\mathrm{g}_{\mathrm{m}}\right)$, and cut-off frequency $(\mathrm{ft})$ of $35 \mathrm{GHz}$. Figure 7 shows a typical graph of the minimum noise figure measured for these devices, when they were biased for minimum noise figure, at both room and cryogenic temperatures. This is a single side band measurement. At higher frequencies, there is a significant improvement in the noise figure at $77 \mathrm{~K}$. In addition, the slope of the noise figure curves decrease from 0.09278 at room temperature to 0.0669 at $77 \mathrm{~K}$. This indicates that at cryogenic temperatures, this device's noise figure becomes less frequency dependent.

\section{SUMMARY}

A microwave, CryoProbe station has been developed that is capable of testing devices and circuits. The station can accommodate both large samples and separate calibration standards simultaneously. When liquid nitrogen is used, the system is ready to perform measurements in just over an hour after the evacuation begins. Cryogenic temperatures are created in a vacuum using either liquid nitrogen or helium. The system can easily be connected to an ANA and noise figure test equipment, to perform automated, temperature dependent measurements.

\section{REFERENCES}

[1] J. Kolodzey, et al., "Cryogenic temperature performance of modulation-doped fieldeffect transistors", Electron. Lett., vol. 25, pp. 777-779, February 1989.

[2] R. Lai, et al., "Low-Temperature Microwave Characteristics of Pseudomorphic $I n_{x} G_{1}$. xAs/In $0.52 \mathrm{Al}$ 0.48As Modulation-Doped Field-Effect Transistors", IEEE Electron Device Lett.,vol. 11, no. 12, pp. 564-566, December 1990.

[3] M. W. Pospieszalski, et al., "FET's and HEMT's at Cryogenic Temperatures- Their Properties and Use in Low-Noise Amplifiers", IEEE Trans. Microwave Theory Tech., vol. 36 , no. 3 , pp. 552-560, March 1988. 
[4] C. C. Yang, "A Cryogenically-Cooled Wide-Band HEMT MMIC Low-Noise Amplifier", IEEE Microwave and Guided Wave Lett., vol. 2, no. 2, pp. 58-60, February 1992.

[5] J. Laskar, and M. Feng, "An On-Wafer Cryogenic Microwave Probing System for Advanced Transistor and Superconductor Applications", Microwave Journal, pp. 104-114, February 1993.

[6 6 G. J. Höfer, F. Jäger, and H.A. Kratz, "Broadband Four-Channel Cryogenic Wafer Probing System for Automated Coplanar On-Chip Measurements", Rev. Sci. Instrum., 64 (3), pp. 788-792, March 1993.

[7] D. d'Almeida and R. Anholt, "Device Characterization with an Integrated On-Wafer Thermal Probing System", Microwave Journal, pp. 94-105, March 1993.

[8] H. Meschede, et al, "On-Wafer Microwave Measurement Setup for Investigations on HEMT's and High Tc Superconductors at Cryogenic Temperatures Down to $20 \mathrm{~K}$ ", IEEE Trans. Microwave Theory Tech., vol. 40, no. 12, pp, 2325-2331, December 1992.

[ 9 ] D. Yang, et al., "Low-Temperature Microwave Characteristics of $0.1 \mu \mathrm{m}$ Gate-Length Pseudomorphic $\operatorname{In}_{0.52} \mathrm{Al}_{0.48} \mathrm{As} / \mathrm{In}_{\mathrm{x}} \mathrm{Ga}_{1-\mathrm{x}} \mathrm{As}$ ( $\mathrm{X}=0.85$ and 0.95 ) MODFETs", Submitted to IEEE Electron Device Lett., January 1994.

[10] R. B. Marks, "A Multi-Line Method of Network Analyzer Calibration", IEEE Transactions on Microwave Theory and Techniques, vol. 39, pp. 1205-1215, July 1991.

[11] S. R. Taub and P. G. Young, "Temperature Dependent Performance of Coplanar Wave guide (CPW) on Substrates of Various Materials", to be presented at the 1994 IEEE MTT-S International Microwave Symposium, San Diego, California, May 23-27 1994.

[12] Hewlett Packard Product Note 8970B/S-2, "Applications and Operation of the HP8970B Noise Figure Meter and HP 8970S Microwave Noise Figure Measurement system."

[13] Hewlett Packard Product Note 8970B/S-3, "Noise Parameter Measurements Using the HP 8970 B Noise Figure Meter and the ATN NP4 Noise Parameter Test Set."

[14] NASA Contract Number NAS3-25931. 


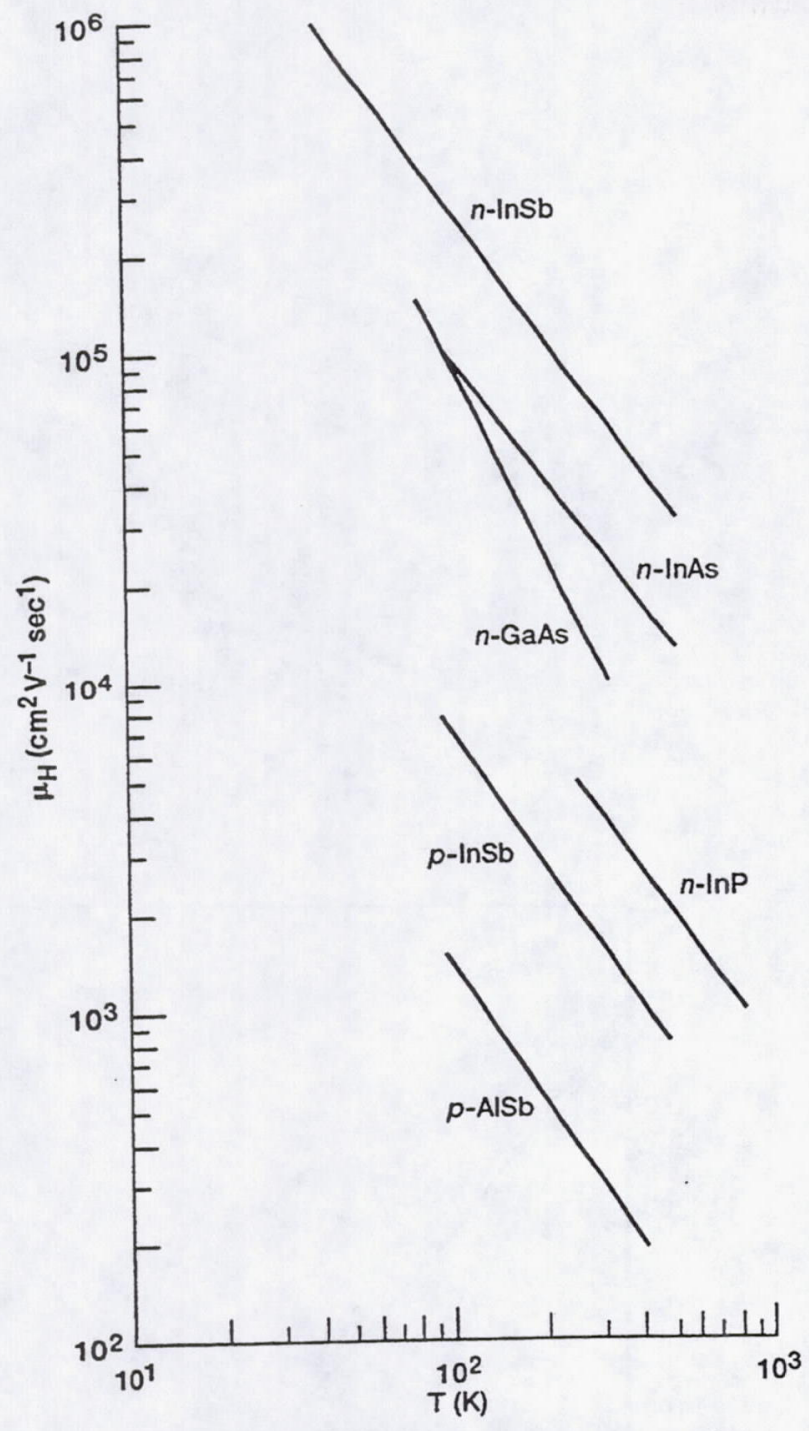

Figure 1.-Hall mobilities of some III-V compounds.

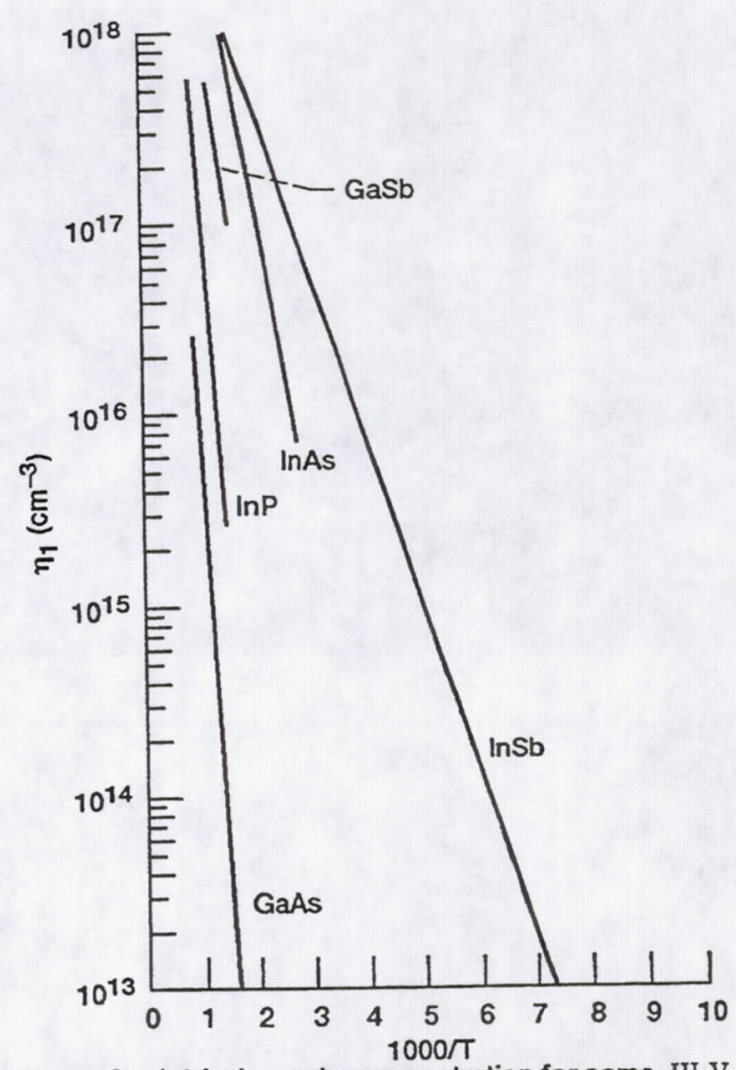

Figure 2.-Intrinsic carrier concentration for some III-V compounds.

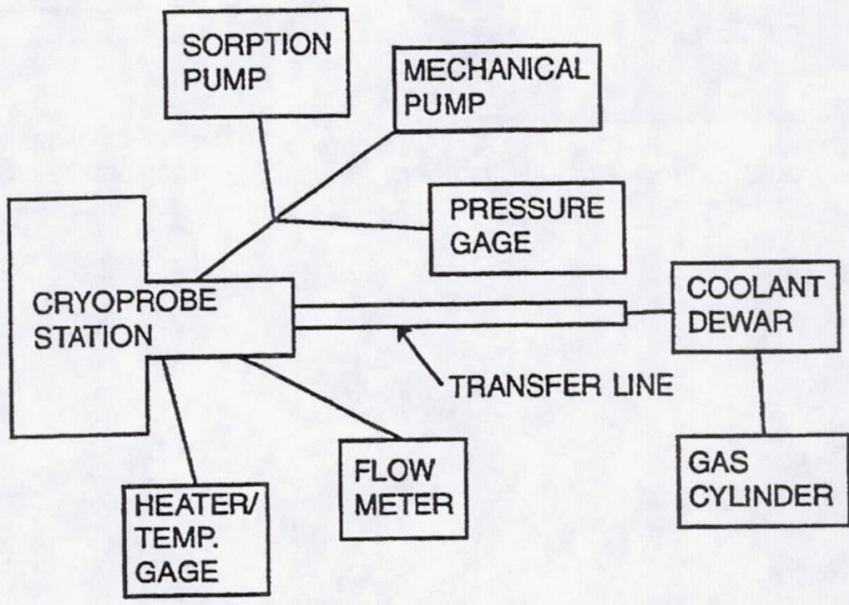

Figure 3.-The CryoProbe Station System. 

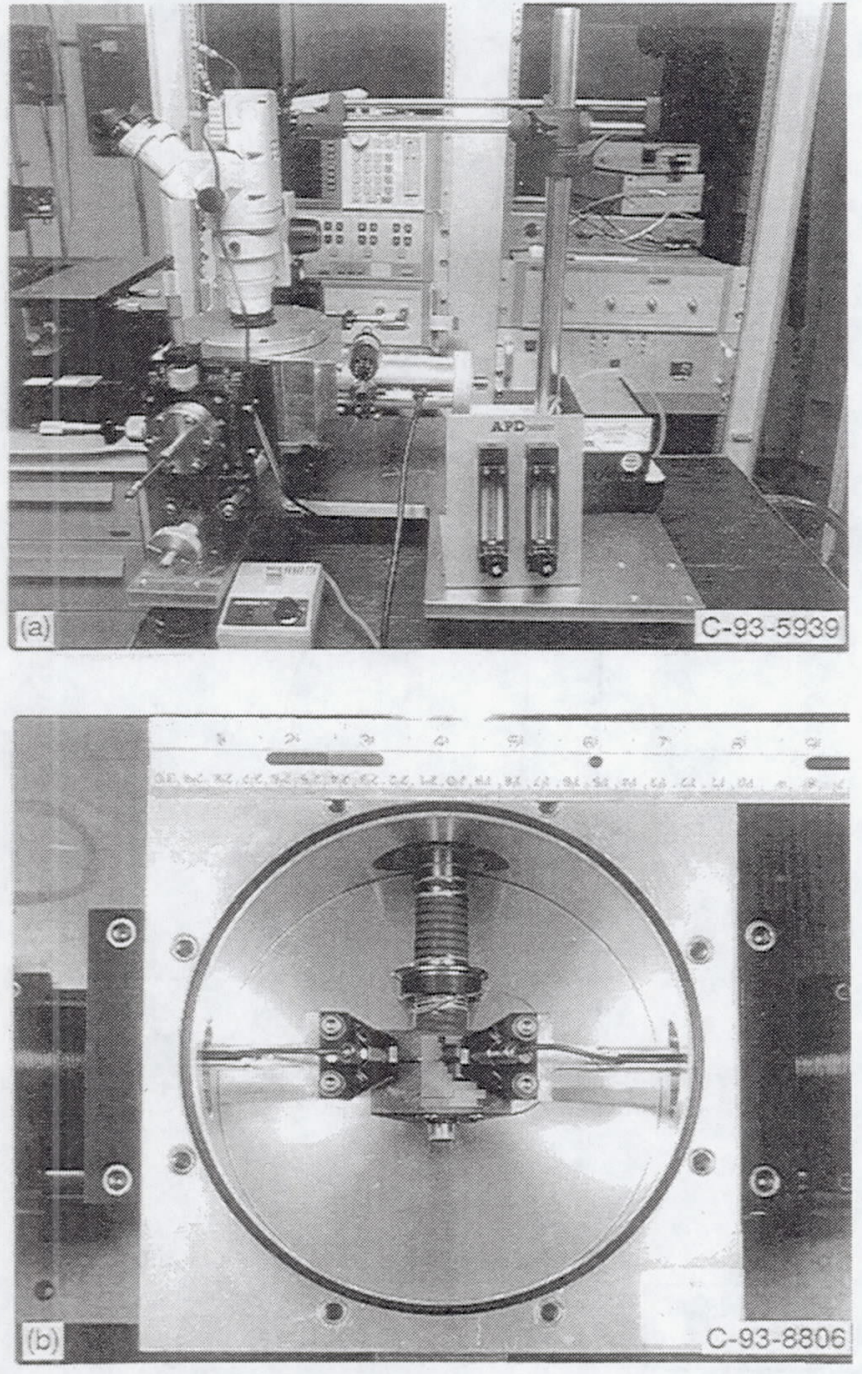

Figure 4.-(a) CryoProbe Station. (b) CryoProbe Station chamber.

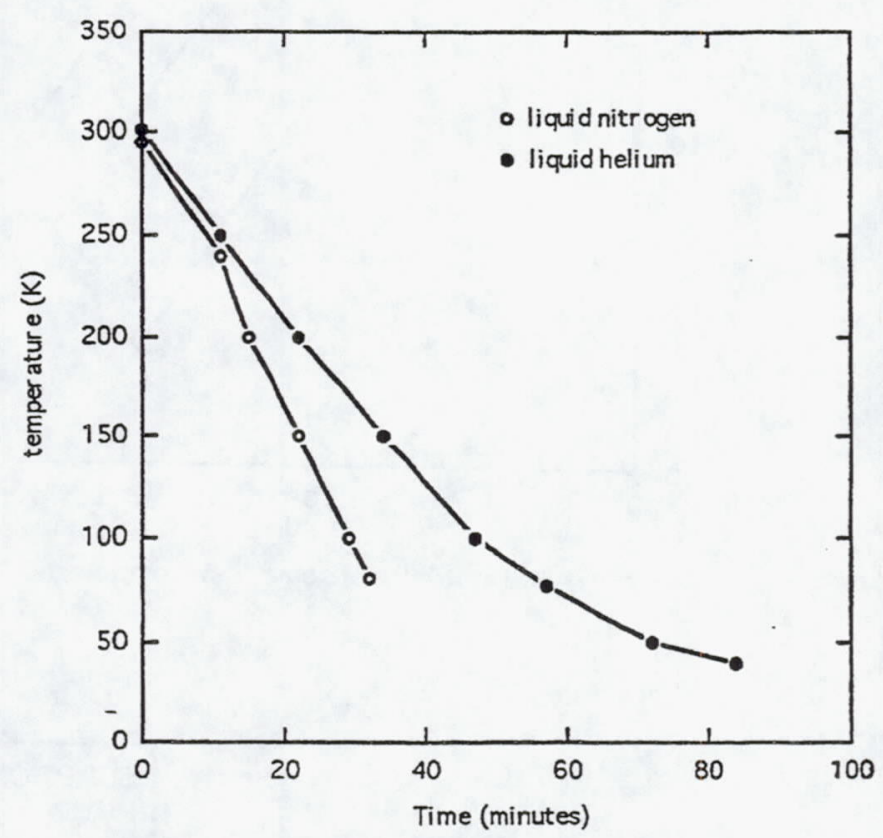

Figure 5.-Cooling times for the CryoProbe Station when liquid nitrogen and liquid helium are used. 


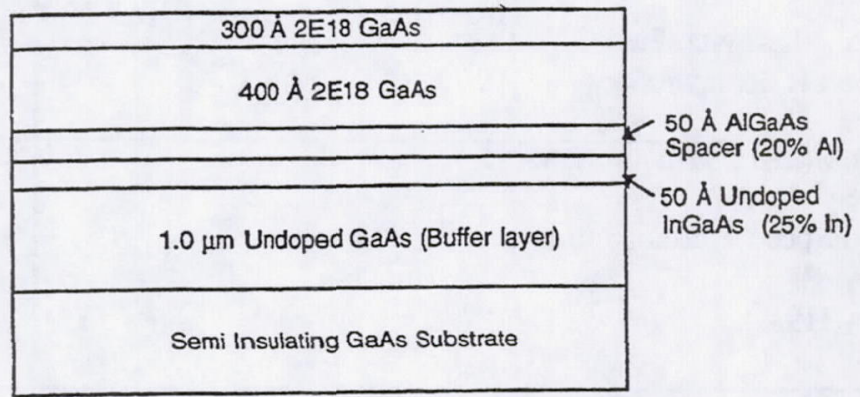

Figure 6.-MOCVD grown HEMT structure.

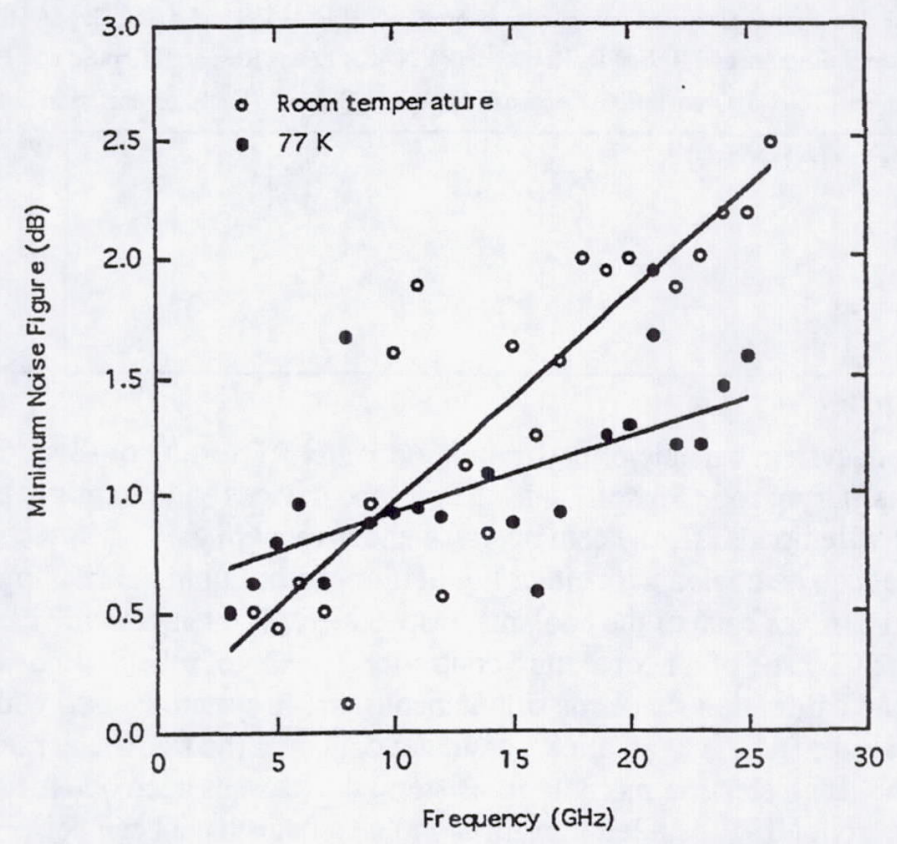

Figure 7.-Minimum noise figure of the $0.25 \mu \mathrm{m}$ MOCVD grown HEMT structure. 
Public reporting burden for this collection of information is estimated to average 1 hour per response, including the time for reviewing instructions, searching existing data sources, gathering and maintaining the data neөded, and completing and reviewing the collection of information. Send comments regarding this burden estimate or any other aspect of this Davis Highway, Suite 1204, Arlington, VA 22202-4302, and to the Office of Management and Budget, Paperwork Reduction Project (0704-0188), Washington, DC 20503.

\begin{tabular}{|l|l|l|}
\hline 1. AGENCY USE ONLY (Leave blank) & $\begin{array}{c}\text { 2. REPORT DATE } \\
\text { March } 1994\end{array}$ & $\begin{array}{r}\text { 3. REPORT TYPE AND DATES COVERED } \\
\text { Technical Memorandum }\end{array}$ \\
\hline
\end{tabular}

\section{TITLE AND SUBTITLE}

Cryogenic Probe Station for use in Automated Microwave and Noise Figure Measurements

\section{AUTHOR(S)}

WU-235-01-0B

Susan R. Taub, Samuel A. Alterovitz, Paul G. Young,

Ben T. Ebihara, and Robert R. Romanofsky

\section{PERFORMING ORGANIZATION NAME(S) AND ADDRESS(ES)}

National Aeronautics and Space Administration

Lewis Research Center

Cleveland, Ohio 44135-3191
8. PERFORMING ORGANIZATION REPORT NUMBER

E-8726

\section{SPONSORING/MONITORING AGENCY NAME(S) AND ADDRESS(ES)}

National Aeronautics and Space Administration

Washington, D.C. 20546-0001
10. SPONSORING/MONITORING AGENCY REPORT NUMBER

NASA TM-106560

\section{SUPPLEMENTARY NOTES}

Prepared for the Automated RF Techniques Group Meeting cosponsored by IEEE, MTIS and ARFTG, San Diego, California, May 27, 1994. Susan R. Taub, Samuel A. Alterovitz, Ben T. Ebihara and Robert R. Romanof sky, NASA Lewis Research Center, and Paul G. Young, University of Toledo, Electrical Engineering Department, Toledo, Ohio 43606. Responsible person, Susan R. Taub, organization code 5630, (216) 433-0571.

12a. DISTRIBUTIONAVAILABILITY STATEMENT 12b. DISTRIBUTION CODE

Unclassified-Unlimited

Subject Category 35

\section{ABSTRACT (Maximum 200 words)}

A cryogenic measurement system capable of performing on-wafer RF testing of semiconductor devices and circuits has been developed. This "CryoProbe Station" can wafer-probe devices and circuits at cryogenic temperatures, thus eliminating the need for wire bonds. The system operates under vacuum created by a sorption pump. It uses an open cycle cooling system that can be cooled with either liquid nitrogen or liquid helium. Presently, it can reach temperatures, as low as $80 \mathrm{~K}$ and $37 \mathrm{~K}$ for each of the coolants, respectively. The temperature can be raised using a heater and it is stabilized to within $0.2 \mathrm{~K}$ by sue of a temperature controller. The CryoProbe Station features a 1 by 2 inch stage that can hold large circuits and calibration standards simultaneously. The system is used with a Hewlett Packard $8510 \mathrm{C}$ Automatic Network Analyzer (ANA) to obtain S-parameter data over the frequency range 0.045-26.5 GHz. Sparameter data on HEMT (high electron mobility transistors) devices has been obtained with this station. With the use of DEEMBED software from NIST, detailed transmission line studies have been performed. Although the CryoProbe Station is designed for frequencies up to $26.5 \mathrm{GHz}$, useful transmission line data has been obtained for frequencies as high as $40 \mathrm{GHz}$. The CryoProbe station has also been used with the ATN noise figure measurement system to perform automatic, temperature dependent noise figure measurements.

\section{SUBJECT TERMS}

Cryogenic; Measurement; On-wafer; Microwave; Probe

\begin{tabular}{|c|c|}
\hline $\begin{array}{l}\text { 17. SECURITY CLASSIFICATION } \\
\text { OF REPORT }\end{array}$ & $\begin{array}{l}\text { 18. SECURTYY CLASSIFICATION } \\
\text { OF THIS PAGE }\end{array}$ \\
\hline Unclassified & Unclassified \\
\hline
\end{tabular}

NSN 7540-01-280-5500
19. SECURITY CLASSIFICATION OF ABSTRACT Unclassified
15. NUMBER OF PAGES 10 16. PRICE CODE $\mathrm{A} 02$ 